\title{
How efficient coding of binocular disparity statistics in the primary visual cortex influences eye rotation strategy
}

\author{
Sarah E Marzen ${ }^{1 *}$, Joel Zylberberg ${ }^{2}$, Michael R DeWeese ${ }^{1,3}$ \\ From Twenty Second Annual Computational Neuroscience Meeting: CNS*2013 \\ Paris, France. 13-18 July 2013
}

Stereopsis, the ability to perceive depth, is crucial for detecting camouflaged objects and for performing tasks that require estimating distance. Understanding how our brain can so quickly estimate depth from the slightly different images from our left and right eyes, the difference of which is called binocular disparity, is still a major unsolved problem in vision research. Several previous computational studies of binocular disparity have found evidence suggesting that various properties of the primary visual cortex (V1) allow V1 to optimally process natural binocular disparity statistics. In particular, the efficient coding hypothesis suggests that the disparity tuning of V1 binocular neurons should reflect the natural range of disparities [1,2]; the cortical wiring hypothesis suggests that the orientation of ocular dominance stripes should follow the binocular disparity map [3]; and visuomotor optimization theory and the efficient coding hypothesis suggests that eye rotation strategy should be chosen to minimize binocular disparity and motor inefficiency $[4,5]$.

In order to understand how natural binocular disparity statistics might be efficiently coded by the primary visual cortex, we constructed a simulation that links natural scene statistics to eye movements to connections between monocular neurons in V1. We generate a three-dimensional visual environment with two-point statistics and observerobject distance distribution similar to that of a natural environment; a virtual observer rotates her eyes according to the binocular version of Listing's Law to fixate on either edges of objects, centers of objects, or randomly chosen points on objects; and the resulting binocular disparities are mapped to V1 by a Schwartz conformal map fit to

\footnotetext{
* Correspondence: smarzen@berkeley.edu

'Department of Physics, U. C. Berkeley, Berkeley, CA 94708, USA

Full list of author information is available at the end of the article
}

physiological data. The effects of two-point statistics, primary Listing's plane exorotation angle, Listing's Law coefficient, and fixation strategy can be revealed using this simulation in ways that would be very difficult (if not impossible) with experiments. For instance, to measure the effect of two-point statistics on binocular disparity statistics using this simulation, we compare the binocular disparity statistics in our more complicated three-dimensional visual environment to a visual environment with the same observer-object distance distribution but no pixel-pixel correlations.

Our simulations show that the predicted ocular dominance stripe orientations and stereoscopic search zones are largely insensitive to two-point statistics of the visual environment, but very sensitive to interocular distance and eye rotation strategy. Finally, our more careful treatment of oculomotor strategy and visual environment shows that physiological oculomotor strategy cannot be explained by current visuomotor optimization theory [5]. A modified visuomotor optimization theory will likely require a better understanding of stereopsis-related processing in the visual cortex.

\section{Acknowledgements}

SM would like to acknowledge the generous funding of NSF GRFP and the U.C. Berkeley Chancellor's Fellowship. MRD gratefully acknowledges support from the McKnight Foundation, the Hellman Family Faculty Fund, the McDonnell Foundation, the Mary Elizabeth Rennie Endowment for Epilepsy Research, and the National Science Foundation through Grant No. IIS-1219199.

\section{Author details}

${ }^{1}$ Department of Physics, U. C. Berkeley, Berkeley, CA 94708, USA. ${ }^{2}$ Department of Applied Mathematics, University of Washington, Seattle, WA 98195, USA. ${ }^{3}$ Helen Wills Neuroscience Institute, U.C. Berkeley, Berkeley, CA 94708, USA. 


\section{References}

1. Read JCA, Cummings B: Understanding the Cortical Specialization for Horizontal Disparity. Neural Comput 2004, 16:1983-2020.

2. Liu Y, Bovik AC, Cormack LK: Disparity statistics in natural scenes. Journal of Vision 2008, 8:1-14.

3. Chklovskii DB: Binocular disparity can explain the orientation of ocular dominance stripes in primate primary visual area (V1). Vis Res 2000, 40:1765-1773.

4. Schreiber $\mathrm{K}$, Crawford JD, Fetter M, Tweed D: The motor side of depth vision. Nature 2001, 410:819-822.

5. Tweed D: Visual-motor Optimization in Binocular Control. Vis Res 1996 37:1939-1951.

doi:10.1186/1471-2202-14-S1-O7

Cite this article as: Marzen et al:: How efficient coding of binocular disparity statistics in the primary visual cortex influences eye rotation strategy. BMC Neuroscience 2013 14(Suppl 1):O7.

\section{Submit your next manuscript to BioMed Central} and take full advantage of:

- Convenient online submission

- Thorough peer review

- No space constraints or color figure charges

- Immediate publication on acceptance

- Inclusion in PubMed, CAS, Scopus and Google Scholar

- Research which is freely available for redistribution

Submit your manuscript at www.biomedcentral.com/submit
C Biomed Central 